\section{A novel method of marking nipple areola complex in gynaecomastia surgery}

Sir,

There are various techniques of management of high grade gynaecomastia. Fat removal by liposuction in 3 planes - intraglandular, supraglandular and subglandular; excision of gland through a periareolar incision from 4 to 8 o'clock position leaving a small button of gland just below the nipple; or both. It should be followed by application of pressure garment for 3 months. Occasionally, after 6 weeks skin tightening device such as unipolar radio frequency may be required. Skin, by way of its elasticity, contracts beautifully.

Our method of management in high-grade gynaecomastia has been single stage subcutaneous mastectomy and circumareolar concentric skin reduction with deepithelisation as described by Tashkandi et al..$^{[1]}$ We always outline $30 \mathrm{~mm}$ diameter nipple areola complex around the existing nipple. The authors of the technique do not mention how they mark the nipple areola complex. In our practice, we have been using a rubber gasket of $60 \mathrm{ml}$ plastic syringe plunger as areola marker [Figure 1]. This measures exactly $30 \mathrm{~mm}$ in diameter and gives a nice round contour to the incised nipple areola complex.

In the majority of operation rooms, the commonly used cookie cutters are $38-42 \mathrm{~mm}$ in diameter, and are meant for female breast surgeries. There are many types of areola markers with different characteristics, but all are primarily devised for female breasts. ${ }^{[2-4]}$

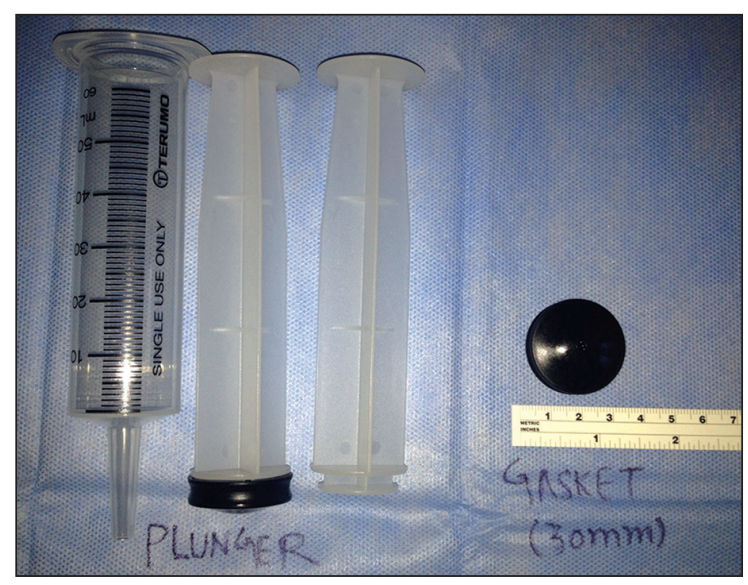

Figure 1: Use of syringe gasket as areola marker
To our knowledge, there is no other alternative reported in plastic surgery literature for marking the male areola.

Our method of using the rubber gasket of the syringe plunger is a cheap alternative and easy to use.

Shabeer Ahmad Wani, Sari M. Rabah, Sara AIFadil, Nieves Vega Saglam Section of Plastic and Reconstructive Surgery, King Fahad Medical City Riyadh, Riyadh, Kingdom of Saudi Arabia

Address for correspondence: Dr. Shabeer Ahmad Wani, Section of Plastic and Reconstructive Surgery, King Fahad Medical City Riyadh, Riyadh, Kingdom of Saudi Arabia. E-mail: wanidrshabir@rediffmail.com

\section{REFERENCES}

1. Tashkandi M, Al-Qattan MM, Hassanain JM, Hawary MB, Sultan $\mathrm{M}$. The surgical management of high-grade gynecomastia. Ann Plast Surg 2004;53:17-20.

2. Köse AA, Karabagli $Y$, Cetin C. A new areola marker. Plast Reconstr Surg 2005;115:1452-3.

3. Cek DI. Custom-made periareolar wavy-line marker. Plast Reconstr Surg 2004;113:454-5.

4. Stocchero IN. An areola marker. Plast Reconstr Surg 2003;111:1776-7.

\begin{tabular}{|l|l|}
\hline \multicolumn{2}{|c|}{ Access this article online } \\
\hline Quick Response Code: & Website: \\
\hline & www.ijps.org \\
\cline { 2 - 2 } & Dol: \\
\hline
\end{tabular}

